\title{
1756: las misiones de guaraníes entre la Ilustración y el etnocidio
}

\author{
1756: Guaraní Missions Between the Enlightenment and \\ Ethnocide
}

1756: as missões de guaranis entre a Ilustração e o etnocídio.

Lic. Diego Joaquín Mellado Gómez*

\section{RESUMEN}

El siglo XVIII marca un proceso de inflexión en los imaginarios

Palabras clave: utópicos y emancipatorios, tanto europeos como en el nacienmisiones jesuitas, te criollismo americano. Analizando algunos acontecimientos que marcaron a la Compañía de Jesús antes de su expulsión y ubicándose en lo que fueron las misiones más relevantes durante su inserción en tierras americanas, este artículo se sitúa en el año 1756, con el fin de comprender sintéticamente las divergencias discursivas que tuvieron lugar a propósito de los procesos de conversión cristiana efectuados por jesuitas a los nativos y perfilar los métodos de las prácticas etnocidas por parte de las autoridades civiles. De esta forma, se exponen elementos que remiten tanto a la génesis y desarrollo del pensamiento ilustrado como a las formas que adquirió la alteridad amerindia para Occidente.

\section{ABSTRACT}

The 18th century marks a process of inflection in Utopian and emancipatory imaginaries, both from Europe and in the budding American criollo identity. Analyzing some of the events prior to the expulsion of the Society of Jesus and the most relevant mis-

Keywords: Jesuit missions, Guarani reductions, colonial frontiers,

\footnotetext{
* Chileno. Licenciado en Filosofía, Universidad de Chile, Diplomado en Edición Profesional, Universidad de Chile. Candidato a Doctor en Estudios Americanos especialidad Pensamiento y Cultura, Instituto de Estudios Avanzados, Universidad de Santiago de Chile. Becario ANID. Tesista en proyecto Fondecyt No 1190337 “Ontología política del placer”. Director de Nadar Ediciones. Contacto: diego.mellado@usach.cl ORCID: https://orcid.org/0000-0003-4799-0681
} 
sions during their insertion in Latin American lands, this article focusing on the year 1756, in order to synthetically understand the discursive divergences that occurred thanks to the Christianity conversion processes of the Jesuits upon the native people and to describe the ethnocide methods and practices performed by the civil authorities. This shows elements of both the genesis and development of enlightened thought as well as the forms acquired by Amerindian otherness for the West.

\section{RESUMO}

O século XVIII marca um processo de inflexão nos imaginários utópicos e emancipatórios, tanto europeus como no nascente crioulismo americano. Analisando alguns acontecimentos que marcaram a Companhia de Jesus antes de sua expulsão e centrando-se naquelas que foram as missões mais relevantes durante sua inserção em terras americanas, este artigo se situa no ano 1756 , com a finalidade de compreender sinteticamente as divergências discursivas que ocorreram a propósito dos processos de conversão cristã efetuados por jesuítas aos nativos e perfilar os métodos das práticas etnocidas por parte das autoridades civis. Desta forma, são expostos elementos que remetem tanto à gênese e desenvolvimento do pensamento ilustrado como às formas que adquiriu a alteridade ameríndia para Ocidente. ethnocide, American Enlightenment

Palavras-chave: missões jesuítas, reduções guaranis, fronteiras coloniais, etnocídio, Ilustração americana. 
Si Dios existe, es perfecto. Si es perfecto, es sabio, poderoso y justo. Si es sabio y poderoso, todo está bien. Si es justo y poderoso, mi alma es inmortal. Si mi alma es inmortal, treinta años de vida no significan nada para mí y a lo mejor son necesarios para mantener el universo. Si se me concede la primera premisa, jamás se podrán destruir las que siguen; si se me niega, ¿para qué discutir las consecuencias?

CARTa a Voltaire, JEAN-JacQues Rousseau (1994 [1756] 17)

\section{Introducción}

La carta que abre este artículo fue firmada con fecha 18 de agosto de 1756. Su remitente, el recordado autor de El Contrato Social (1762), plantea a su destinatario un conjunto de críticas referidas al Poema sobre el desastre de Lisboa o Examen de este axioma: «Todo está bien». En estos versos, Voltaire inquiría los argumentos teológicos, contraponiendo la recién acaecida tragedia del terremoto de Lisboa $(1755)^{1}$ a la metafísica leibniziana. El impacto de este devastador terremoto repercutió en el mundo ilustrado europeo, transformándose prontamente en un dilema respecto a la conciliación entre Naturaleza y Razón. Escribe Voltaire: “Ante el espectáculo espantoso de sus cenizas humeantes, / ¿Diréis: "Es el efecto de las leyes eternas / Que necesitan la elección de un Dios libre y bueno?»" (v. 15-17), dando paso a una discusión contra los sistemas filosóficos que, bajo el axioma "todo está bien" y "todo es necesario", no lograban dar respuesta al origen de los males morales y físicos. Rousseau, tras leer estos versos, incentiva un debate que busca definir códigos civiles respecto de la religión y el Estado, emprendiendo un catecismo cívico a la luz del derecho natural y la Providencia. No obstante, a Voltaire no le interesa discutir: “(...) en este momento me habrá de perdonar si dejo de lado esas discusiones metafísicas, que son solo pasatiempos", le responde.

Sin adentrarse en el trote filosófico ${ }^{2}$, surgen de esta anécdota ciertos aspectos que orientan las discordancias que analizaremos: primero, se

\footnotetext{
Este terremoto, acontecido el 1 de noviembre de 1755 en las costas portuguesas, ha quedado archivado en los anales sísmicos como un magno movimiento telúrico al que le siguió un maremoto y el incendio de Lisboa. Ocurrido el día de Todos los Santos, a la hora de la misa mayor, causó estragos en Portugal, España, Marruecos y Argel, produciendo miles de víctimas, aproximadas entre 60.000 y 100.000 (Martínez Solares).

2 Respecto de la discusión Rousseau/Voltaire, ver: En torno al mal y la desdicha; Voltaire-Rousseau, edición de Alicia Villar (1995) y Rousseau, J.-J., Escritos polémicos (1994).
} 
trata de una discusión entre dos insignes figuras de la ilustración francesa, debatiéndose en los límites de la razón y de la teología; segundo, que el trasfondo de un desastre natural remite a un proceso geológico que afectó en la evolución intelectual, no solo por su nivel de devastación, sino también porque devino en objeto de estudio, tanto en un nivel filosófico y teológico, como en el sentido de las ciencias físicas y el nacimiento de la sismología como rama de investigación; tercero, porque es el año 1756, cruzando la mitad del siglo XVIII, época en que los conflictos suscitados por la legitimidad de los Estados coloniales se abrían paso bajo el amparo del derecho divino -compuesto como sistema jurídico, gubernamental y militar inspirado en la obediencia al Rey, eslabón de la divinidad con el poder político-, y de las proyecciones universalistas adquiridas por la expansión del cristianismo como lente de conocimiento de la alteridad. En otras palabras, esta anécdota representa un umbral en el que comienza a trazarse la imagen del buen salvaje como horizonte que determina los caracteres del derecho natural y, por ende, del orden civil, ampliando los campos de la racionalidad a un hecho originario: el hombre natural, resultado abstracto del orden de lo virtual (Deleuze 36), inspirado sobre todo en la literatura etnográfica, género que para ese entonces ocupaba un importante espectro de la producción bibliográfica francesa y anglosajona ${ }^{3}$.

El presente artículo, reconociendo estos elementos dentro de lo que venía gestándose en Europa bajo el nombre de "Ilustración", contrasta las discusiones suscitadas por el cultivo de saberes etnográficos, en cuanto metodología científica reductiva con las formas autonómicas, indígenas y criollas que, desde perspectivas divergentes, se desarrollaron a la par en el continente americano. Esto acarrea la pregunta implícita relativa al manejo de narrativas que, aunque camufladas de un conocimiento verídico, promovían imágenes acopladas a las formas de comprensión (censura, categorías, catálogos, cartografías) y

\footnotetext{
Como planteó tempranamente el erudito brasilero Alfonso Arinos de Melo Franco, la teoría de la bondad natural era un directo correlato de las narraciones sobre el indio americano - y sobre el brasilero en especial— difundidas en Europa desde la Conquista, pasando del "motivo literario, o, como máximo, del concepto filosófico y jurídico que era en los siglos anteriores, a constituir un verdadero principio político, generador de las más graves consecuencias doctrinarias" (2000 [1937] 223): al retrato del indio desnudo, emulación del edén, le siguió el imaginario de un estado de naturaleza transparente, aunque siempre equívoco, repartido entre el Leviatán hobbesiano y el Contrato Social rousseauniano.
} 
de acción política europeas (conversión religiosa, guerra, diplomacia). Este simultáneo campo ficcional y factual se desplaza en códigos diversos, que van desde el nacimiento de utopías hasta la apropiación de un Otro exótico al que se ubicó en las antípodas de la civilización. Para analizar estas bifurcaciones, dirigiremos la discusión hacia la lectura de contradictorios documentos sobre un crucial evento del siglo XVIII.

\section{Utopías en las fronteras}

El siglo XVIII constituye un umbral cognitivo que transformó los imaginarios de las utopías occidentales: la carrera empírica del cristianismo utópico en América se desenvolvió como una de las ramas de la Conquista, mutando posteriormente en objeto de emancipación dentro de los engranajes de la historia universal (Aínsa), proyecto epistemológico característico del iluminismo ilustrado y enciclopédico que comenzaba a perfilar los clásicos ideales de progreso del siglo XIX. Esta inflexión utópica quedó claramente expuesta por la situación que afectó a la Compañía de Jesús, en cuanto periodo que comprendió la expulsión de los dominios ibéricos ${ }^{4}$ se bifurca entre el ocaso de un plan civilizador y la emergencia de un pensamiento criollo que, a causa del exilio, insertó la palabra americana en el mundo europeo. El diálogo entre estos dos planos se unía a través del emprendimiento jesuita en relación a la producción de historias naturales y civiles acerca de los habitantes y del territorio americano: estas obras, redactadas en el mismo continente o en el exilio, operaban como método de reducción de la diversidad, figurando la dimensión científica como narraciones descriptivas de los eventos naturales y sociales, articuladas de acuerdo a marcos deductivos que, estructurados de lo general a lo particular, de lo natural a lo cultural, de lo salvaje a lo moral, concatenaban clasificaciones y reinos desde lo simple a lo complejo ${ }^{5}$.

\footnotetext{
4 De los dominios portugueses son expulsados en 1759, mientras que de los españoles en 1767. Francia también forma parte de este antijesuitismo, tomando la misma medida en 1762. En todas las ocasiones se presentaron cargos relativos a sublevaciones contra la monarquía.

$5 \quad$ No está de más imaginar el conflicto teológico tras este afán científico por parte de los jesuitas. Ciertamente, la percepción ocular cumple un rol esencial en el ejercicio epistémico de estas historias naturales, representando un singular evento literario en cuanto narrativa aliada a la observación directa. Esta habilidad era parte del ambiente intelectual que fue forjando la Ilustración y que, en su debate contra la escolástica, se posicionó como una nueva instrumentalización corporal. Los jesuitas, en los
} 
Se trata de una extensa bibliografía jesuita forjada entre los siglos XVI y XVIII, que versó acerca de los territorios que colonizaron en un nivel testimonial o personal (diarios, cartas) y en relatos objetivantes sobre el mundo natural y la vida cívica ${ }^{6}$. Este abanico misional llegó a extenderse en todos los puntos cardinales, alcanzando especial arraigo en América, donde las riveras platinas y sus alrededores constituyeron la experiencia más exitosa (Klaiber), tanto en el ámbito de su extensión cronológica (un siglo y medio de "civilización") como en los impactos y opiniones que suscitó en los círculos intelectuales de Europa ${ }^{7}$. Si bien el espacio misionero, conocido también como los Treinta Pueblos, ha sido clasificado en los archivos históricos como un Estado "colchón" (Armani) que permeó las relaciones en una región fronteriza y problemática para las Coronas ibéricas, lo cierto es que se trata de un territorio complejo, no solo por su errática ubicación, sino también por las nomenclaturas y cambios que comienzan junto con la Conquista, entre los que podemos nombrar, por ejemplo, la modificación del paisaje por la arquitectura, la ganadería y nuevos regímenes de propiedad; la conversión de grupos nativos al credo cristiano y la subsecuente localización de espacios sagrados; la militarización, la esclavitud y el trabajo como posibilidades latentes del cotidiano vivir.

Evidentemente, cada uno de estos aspectos contó con particulares desarrollos a través de la historia misionera, integrando una red

bordes de la teología natural y la racionalidad científica, tensionaban un elemental debate cristiano expresado por San Agustín (Conf. X 35) cuando, refiriéndose a la concupiscencia de los ojos, exhorta a fijar la mirada únicamente en Dios, apartando tanto la tentación del cotidiano vivir como las atracciones de la ciencia. La solución a este dilema resultó clara, considerando que no había separación entre religión y política. Los jesuitas, miembros de una orden cristiana, eran ante todo funcionarios y, como tales, estaban acoplados al sistema colonial monárquico, al cual obedecían y enriquecían. En este sentido, la tarea del funcionario era observar y encontrar la conexión divina en el mundo natural haciendo uso de sus instrumentos y metodologías lógicas. La concupiscencia se obnubilará ante la presencia del Dios ordenador, presente incluso en la desordenada naturaleza de la selva y vivo como potencia en los espíritus de los salvajes nativos.

${ }_{6} \quad$ Entre los referentes jesuitas de este género durante el siglo XVIII destacan: José Gumilla en las rutas fluviales del Orinoco (1974 [1741]); Francisco Javier Clavigero para México (1974 [1780]); Juan Ignacio Molina respecto al Reino de Chile (2010 [1776]); Juan de Velasco en Quito (1981 [1789]); Pedro Lozano para el Paraguay, Río de la Plata y Tucumán (1873).

$7 \quad$ Para una lectura sintética de las versiones naturalistas efectuadas por jesuitas de la región platense, con especial énfasis en la obra de José Sánchez Labrador, revisar el magno estudio Misiones y sus pueblos de guaranies de Guillermo Furlong (34-70). 
de interacciones no reducibles al ámbito cívico. Por ahora, interesa desmembrar parte de la operación epistémica detrás del carácter científico de estas obras, considerando, por un lado, que durante el contexto colonial primó un criterio realista y autorial "narrativamente determinado por la necesidad de informar y referir los hechos de la conquista junto con mantenerse a resguardo de las prohibiciones de escribir mentirosas historias" (Hachim y Hurtado 174) y, por otro lado, que el sentido de las categorías clasificatorias pretendía compactar la diversidad y complejidad de la alteridad amerindia, acoplándola dentro de una comprensión teológica y científica a la vez. Estas dos características moldearon la relación entre los jesuitas y los nativos, instaurando una nueva forma de apropiación de los espacios conquistados:

Los imperativos para la intervención misionera en Paraguay fueron establecidos por producciones locales e internacionales de conocimiento etnográfico. Escribiendo para un público europeo de élite y de clase media, miembros de su orden y funcionarios de la corona, los Padres paraguayos produjeron historias civiles y naturales que reclamaban la posesión de los guaraníes y otras poblaciones indígenas al documentar las respuestas de los indios a la fe católica y al naturalizar su aceptación, resistencia y comunicación continua como las acciones de los sujetos cristianos (Huffine 280).

De acuerdo con esta posición, se infiere una contradicción: dueños de un relato neutralizante, la imagen purificada y destilada por la censura que promovía la narrativa jesuítica sobre sus proyectos misioneros y sus relaciones con los grupos indígenas, constituye una particular invención repartida entre lo real y lo ficticio ${ }^{8}$. Al hecho

\footnotetext{
$8 \quad$ Ejemplo de ello es la obra El cristianismo feliz en las misiones de los padres de la Compañia de Jesús en Paraguay, escrita por Ludovico Antonio Muratori (1997), uno de los principales referentes de la "Ilustración católica" italiana, quien, sin viajar a tierras paraguayas, pero inspirado en informes, relatos de viajes y cartas, retrató el idilio jesuita. Mario Góngora (225) señala que "la relación entre cristiandad y felicidad (...) implicaba una urgencia apologética por demostrar la posible identificación de las religiones tradicionales y otras de ámbito universal con la nueva idea moral y social, mostrando que esta fusión se estaba llevando a cabo fuera de Europa". El criterio de Muratori es comparable con la analogía entre la república platónica y las reducciones, entrevista implícitamente por Montesquieu y desarrollada por el jesuita catalán José Manuel Peramás (Ibíd.). Para una lectura de los juicios de Raynal, D’Alembert, Voltaire y otros ilustrados bifurcados entre los pro y los contra, ver: Hernández, Pablo (412-509).
} 
histórico, hoy vigente como ruinas entre cuatro naciones americanas (Argentina, Paraguay, Uruguay y Brasil), le siguen un conjunto de mitos que borran los matices y modulaciones de lo que, claramente, fue una experiencia compleja, no reductible al sencillo hito utópico o a la tiranía económica, sino más bien situada en un contexto de relaciones geopolíticas en el que lo religioso no es más que un elemento dentro de un plan de control mayor.

Así es como de esta operación resulta no solo la síntesis de la bondad natural, sino también lo que ha sido denominado una "etnografía estatal", emprendimiento cognitivo que configura las fuentes históricas mediante la articulación de la tríada "conocer, tomar y destruir" (Cordeiro Ferreira). Como plantea el antropólogo Guillermo Wilde, "las 'etnografías estatales' legitimaban los intereses y la acción del Estado por medio de la exposición de un conocimiento que era considerado puro. En ellas el discurso sobre la diferencia era revestido de una aparente neutralidad universalista" (2003 111). Parte de esta neutralidad era definida a partir de las analogías respecto a lo idílico y lo infernal, perfilando criterios que articularan la "división tipológica entre salvajes y civilizados", como escribió Pierre Clastres respecto al paso del Tiempo a la Historia que caracteriza la aparición del Estado (176). Por ejemplo, el jesuita José Cardiel, en una obra de título Declaración de la verdad contra un libelo infamatorio impreso en portugués contra los PP. jesuitas misioneros del Paraguay y Marañon-empeñada en excomulgar a los integrantes de la Compañía de todo vínculo con la insurrección indígena que luego analizaremos-, describe el mundo espiritual guaraní previo a la labranza civilizadora del siguiente modo:

Esta nación guaraní era de las más bárbaras del mundo: todos eran caribes sangrientos (caribes llaman en todo la América a los que son comedores de carne humana); continuamente andaban en guerra unos con otros. A los que mataban se los comían luego. A los que cogían vivos, los engordaban como a cebones y después se los comían. Vivían en rancherías o pueblecillos de 16, 20 o más chozas de paja con un cacique que los gobernaba, porque entre ellos no había justicia alguna, ni más castigo que el matar, y el juez y el verdugo era la parte agraviada. Sembraban algo, y lo que no alcanzaba para la siembra, lo buscaban cazando, pescando o haciendo guerra 
para solo tener hombres que comer. La hechicería, la borrachera, la poligamia o pluralidad de mujeres con una más que bestial lujuria, eran sus ordinarios vicios que entre ellos tenían por grandes virtudes (Cardiel 272-273).

José Cardiel aclarará: "Acometieron los jesuitas a ganar este reino del infierno". Otros ejemplos podrían sumarse acerca de las percepciones del encuentro entre cristianos y nativos, sobre todo en territorios que, al carecer de las riquezas minerales presentes en los otros focos de la Conquista, no fue de interés directo de la Corona, desarrollándose la invasión a través de agentes nulamente coordinados entre sí y en permanente conflicto de intereses.

Por estas razones, el espacio misionero paraguayo continúa siendo paradigmático hasta nuestros días. Bajo las capas de las espesas y extensas bibliografías jesuita, antijesuita o netamente nacional-militares, se ha logrado poner de relieve elementos solapados por estas narraciones históricas, cobrando un rol protagónico la capacidad de agencia indígena en términos de poder político (Quarleri 2009), los alcances de la alfabetización y de la escritura (Neumann), y la permeabilidad de las reducciones respecto a la división entre espacio fiel y espacio infiel (Wilde 2009), distintivo de las relaciones entre indígenas "conversos y reducidos" y los que aún mantenían sus dinámicas autónomas de la Corona y el cristianismo.

En síntesis, a mediados del siglo XVIII, la correspondencia entre un pensamiento ilustrado y la información extraída de la naturaleza y sus estados (terremotos, selvas, animales y "humanos salvajes", u otras formas de alteridades físicas o morales), simulan un imaginario reductivo y neutralizante que constituye la operación universalista, dentro de la cual se traduce y clasifica la función y utilidad del Otro en los esquemas de control territorial. En este sentido, para los efectos del presente artículo, ubicados paralelamente a la discusión entre Rousseau y Voltaire, es decir, en el año 1756, nos centraremos en las fronteras coloniales, específicamente los meandros platenses que en dicha década se disputaban entre las fuerzas imperiales luso-españolas y los pueblos indígenas guaraníes de las reducciones, sublevados contra la expulsión obligatoria decretada por las Coronas ibéricas. 


\section{Variaciones del guaraní criollo}

El siglo XVIII constituye el eslabón entre la Colonia y la colonialidad. Como observó Aníbal Quijano, la situación colonial se perpetuó actualizándose mediante la occidentalidad del poder, evento que, como notaremos, se perfila conflictivamente en las fronteras luso-hispánicas ${ }^{9}$. En efecto, los márgenes coloniales no solo eran equívocos a causa de los erráticos trazados limítrofes, sino sobre todo por las condiciones lingüísticas que se forjaron a partir de la interacción entre colonos y nativos. Por ello, la reconstrucción de las comunicaciones en las extensiones del mundo guaraní-misionero resulta problemática, sobre todo en contextos en los que la producción de informaciones aumenta en función de conflictos que implican coordinación diplomática, ordenanzas o comunicados, visibilizando distancias lingüísticas que, en los espacios fronterizos, contraponen nociones divergentes sobre los modos de habitar el territorio.

De este modo, se observa cómo los colonialismos, al lanzarse en la destrucción de sistemas indígenas, llegaron a producir mayor cantidad de informaciones catalogadas como "saber oficial" dentro de los bordes de las historias civiles y las cartografías. Sin embargo, más allá de estas narrativas, para comprender las texturas de la época es necesario contraponer documentación que va desde los diarios de viaje, cartas, documentos públicos, comunicados, poemas, cantos, incluyendo imágenes como mapas, ilustraciones y grabados relativos a los paisajes. Ciertamente, se trata de una época de amplia didáctica en torno a las formas de textualidad y que, en el caso de las misiones paraguayas, adquiere un sentido discordante, en tanto durante el siglo XVIII se acentúan diferencias entre formas de comunicar la lengua guaraní.

$9 \quad$ Resulta interesante tensionar el sentido que comienza a adquirir la colonialidad del poder, explicitando los ejes que Aníbal Quijano, desde el contexto andino, plantea respecto de la configuración de un patrón epistemológico que se encauza como racionalidad instrumental o tecnocrática, actuando sobre las sociedades amerindias como mutación y no como continuidad. Estos ejes pueden resumirse como: 1) clasificación e identificación social sobre la idea de "raza"; 2) despojo y represión de las identidades originales, definiendo lo indio como una identidad negativa; 3) distribución de identidades sociales como ordenamiento de las formas de explotación y control; 4) continuidad de patrones de poder que reproducen nuevas identidades históricas, jerarquizan la relación entre europeos y no-europeos y fundan instituciones para preservar los nuevos fundamentos de clasificación social; 5) comprensión de las poblaciones indígenas como subculturas a propósito de su iletrismo; 6) impedimento de prácticas autonómicas, tanto en un nivel territorial como estético (Quijano). 
Si bien el proyecto reduccional jesuítico se concretó bajo un marco disciplinar, económico y arquitectónico, una de sus principales iniciativas fue la reducción de la lengua guaraní a la escritura, la gramática y el diccionario. Para Bartomeu Melià (80-93), esta labor filológica de los jesuitas correspondió a una apropiación de la lengua guaraní, a la que habrían dado el rango de una lengua general, "civilizada" y, por ende, configuradora de una identidad nacional. En tal sentido, los tres ejes de la reducción lingüística pueden plantearse en los siguientes términos: 1) la reducción a la escritura permitía adquirir el prestigio de la letra, llegando a ser impresa y elevándola a nivel de lengua culta y estandarizada; 2) la reducción gramatical, tarea emprendida desde el Padre Antonio Ruiz de Montoya en 1640, pretendía una forma común de hablar, útil a los sermones y a las escuelas, a modo de sobrellevar las diferencias dialectales de las poblaciones reducidas; 3) la reducción a diccionario representaría el carácter transicional en la reestructuración semántica de las palabras en vista a un nuevo discurso religioso, a la vez que funcionaría como objeto de conversión interna.

Esto provocó que, a lo largo del periodo colonial, el territorio que comprendía las Misiones se distinguiera lingüísticamente de otras comunidades que cohabitaban aledañamente, llegando a gestarse otra lengua guaraní, "jerigonza bastardeada, si se quiere, pero que era hablada por todo un pueblo, que se hispanizó culturalmente, sin dejar de hablar guaraní" (Id. 300). No obstante, en las reducciones, el castellano, como hecho social y habla ordinaria, nunca logró insertarse: aunque en el guaraní jesuítico se hayan inmiscuido un caudal considerable de hispanismos, "la práctica lingüística más común fue la creación de neologismos y de nuevos modos de decir que, poco a poco, por lo menos a nivel de literatura, también colonizaban al guaraní" (Id.96).

En estos términos, se plantea un hecho singular: el denominado "guaraní" posee cierto hilo común entre sus hablantes, pero su sentido se define por su diferencia y las variaciones que lo transforman a través de selvas, ríos, montes y costas. La variante jesuítica, en este contexto, llegó a ser una de sus versiones, articulada como simiente de una identidad nacional anexada a una organización de tipo estatal. Pese a su extinción después de la disolución de las reducciones, jugó un papel fundamental en lo que más delante se configuró como división lingüística entre los espacios públicos y domésticos: “la vida pública será 
dicha en castellano; la vida doméstica se expresa en guaraní" (Id. 66). Uno de los matices más destacables de este devenir lingüístico-guaranítico de carácter ilustrado, es la aparición de una imprenta itinerante. A comienzo del siglo XVIII, gracias al jesuita austriaco Juan Bautista Neumann y al jesuita español José Serrano, se instaló una imprenta y se fabricaron los tipos móviles en las reducciones, publicando hacia el 1700 la primera obra en la misión de Loreto: Martirologio romano, de Dionisio Vázquez. A esta obra, le siguió en 1705 el permanente bestseller jesuita De la diferencia entre lo temporal y eterno, de Eusebio Nieremberg, sumando posteriormente obras relativas a la moral cristiana, como Instrucción práctica para ordenar sanamente la vida de Antonio Barriga, y a la enseñanza de la lengua, específicamente de Ruiz de Montoya. La construcción de esta biblioteca multilingüe tuvo su hito cuando, en 1724, el cacique Nicolás Yapuguay publicó una obra de su autoría en guaraní: Explicaciones del catecismo en Lengua Guaraní, a la que le siguió Sermones y exemplos en Lengva Guaraní en 1727 (Gil). Al respecto, Antonio Astrain agrega una peculiar observación sobre las capacidades miméticas y manuales de los nativos, señalando que las letras y las láminas de metal fueron manufacturadas por los propios indios, transformados en tipógrafos hábiles en un proceso imitativo similar a la confección de esculturas en madera de santos católicos.

Estos avances técnicos e intelectuales no eran homogéneos a toda la vida reduccional. Al contrario, eran exclusivos de los cacicazgos, posicionados en el sistema misionero como administradores ocupados de cargos públicos. Las capacidades letradas, en este sentido, eran sinónimo de prestigio y ampliaban los códigos comunicacionales a un bilingüismo que, en momentos de enfrentamiento con las potencias coloniales, se tornará problemático e insostenible para el ámbito de la interpretación.

\section{1756, conocer para destruir}

En juicio del historiador John Lynch (2001), para esta época, debido a que las Coronas se encontraban a ultramar, se habían desarrollado localmente elites que, en tanto empresas privadas surgidas de la misma conquista, se encargaban de influenciar y manipular la burocracia en favor de sus intereses económicos. En estas fluctuaciones, se firmó un nuevo tratado limítrofe en 1750, conocido como Tratado de Madrid, el 
cual permutaba Colonia de Sacramento, asentamiento portugués ubicado en la costa platense, por los siete pueblos de las reducciones ubicados en el lado oriental del Río Uruguay. Esta demarcación actualizaba y detallaba los antiguos paralelos del Tratado de Tordesillas (1494), estableciendo las áreas de influencia de cada monarquía mediante un método diplomático que no implicara el enfrentamiento bélico, como ya había ocurrido en sucesivas ocasiones desde la fundación de Colonia en las puertas de Mar del Plata ${ }^{10}$.

Se ordenó, entonces, el desplazamiento de siete Misiones: San Borja, San Antonio, San Juan Bautista, San Nicolás, San Luis, San Miguel y San Lorenzo, desencadenando la denominada "guerra guaranítica" (1753-1756 $)^{11}$. Esta movilización comprendía un total de 30.000 habitantes que serían reubicados en los dominios hispanos. Si bien la orden, supuestamente, fue acatada en un comienzo, erráticas señales durante la peregrinación y la oposición de una de las reducciones die-

10 La historiografía canónica y eurocéntrica ha abordado este evento con marcado sesgo ideológico. Por dar algunos ejemplos, véase una voluminosa obra como Historia de América de M. Hernández Sánchez Barba (412), en ese entonces director del Departamento de Historia de América de la Universidad Complutense de Madrid, que, al repasar este evento histórico, solo hacer notar que el Tratado de Madrid fue una adelantada visión de contratos internacionales, en cuanto estableció "una colaboración hispano-portuguesa en la acción contra cualquier invasor procedente de cuerpo nacional extraño", siendo por ello un antecedente de un siglo de la Doctrina Monroe. Mismo juicio expresó, años antes, John Hemming desde la editorial de Harvard: "The pragmatic and cordial spirit of the Treaty of Madrid was lost, and the matter became part of European power politics - largely because of the Tape Indians' defiant refusal to leave their traditional homelands" (Hemming 1978). En la misma línea, Hemming destaca la singularidad del indio cristiano cuando al claudicar la guerra con la batalla de Caibaté el 10 de febrero de 1756 bastaron pocos minutos "para que la artillería y la caballería de los europeos dieran muerte a 1.400 indios cristianos que enarbolaban patéticamente sus pendones, crucifijos e imágenes santas" (Hemming 1990).

11 Sin duda, la noción de "guerra" adquiere en este contexto un sentido distinto o particular. Ya tendremos ocasión de analizarlo. De momento, en contraposición con las historiografías académicas sobre este conflicto limítrofe, las posteriores investigaciones realizadas por los mismos jesuitas abrieron el campo a nuevas documentaciones, ordenadas y presentadas desde el ángulo de la participación marginal de los misioneros y anulando las modulaciones y coordinaciones de la resistencia indígena. En este ámbito, son elementales las obras de Francisco Mateos y Guillermo Kratz. Dentro de la producción actual latinoamericana, tres obras destacan por sus enfoques: etnohistórico, centrado en estudios de documentos, en el caso de Lia Quarleri (2009); antropológicohistórico, articulado desde la agencia indígena, en la perspectiva de Guillermo Wilde (2009), e histórico, con énfasis en la relación con lo sagrado, en la lectura de Tau Golin. En el ámbito testimonial, son fundamentales los registros de Bernardo Nusdorffer, basado en el relato del indígena Crisanto Nerenda sobre el enfrentamiento contra los portugueses en Río Pardo en 1754, y de Tadeo Henis, jesuita checo y cura de San Lorenzo, que acompañó las primeras avanzadas de la resistencia guaraní durante 1754 . 
ron paso a la resistencia guaraní frente a la migración impuesta. Cabe señalar, además, que la relación entre guaraníes y portugueses era de un trato imposible: bandeirantes esclavistas, destructores de estancias, ladrones de mujeres, eran algunas de las acusaciones que surgían de la memoria indígena frente a los que consideraban sus enemigos históricos.

De esta forma, las agudizaciones políticas de los años siguientes marcaron el choque de perspectivas y lenguajes que solo dieron tregua bajo la imposición del fuego de la artillería monárquica. En esta pugna se reconocen distintas posiciones: la estatal-colonial, configurada desde la institución militar y las elites creadoras de riquezas; la religiosa-jurídica, como representación de un imaginario universalizante que otorga un valor trascendental al ser cristiano como sujeto de derechos, y lo indígena, bifurcado entre la conquista espiritual y la insurrección contra el desplazamiento ordenado por las Coronas luso-españolas ${ }^{12}$.

En esta multiplicidad de orientaciones discordantes que promueven los ámbitos políticos y territoriales, la figura del intérprete se diluye en laberintos semánticos alejados de la condición diplomática propia de las comunicaciones en contextos conflictivos, articulando la palabra indígena en el ámbito de un "discurso extraño"13. Esto llevará a los jesuitas a señalar que, en los trágicos desenlaces de esta guerra, la falta de fidelidad por parte de los intérpretes tuvo un rol fundamental. Bartomeu Melià (65), acorde a esta afirmación, plantea la disonancia interpretativa citando a José Cardiel en Compendio de la historia del Paraguay (122):

12 Quarleri reflexiona, desde el ángulo de la investigación histórica, acerca del desafío metodológico que implica el estudio de la guerra guaranítica a propósito de las múltiples fuentes que se disponen sobre este periodo (crónicas, cartas, interrogatorios), sobre todo si se aspira a descifrar la participación de los guaraníes en el conflicto (2011). Quarleri, en este sentido, menciona un elemento importante en relación a las fuentes no jesuíticas: las autoridades civiles nunca prestaron atención a las demandas de los indígenas, dado que "los jesuitas eran los principales agentes de la rebelión", mientras que los guaraníes eran "una cultura inferior que necesitaba tutela y disciplina permanente" (128).

13 La tesis del "discurso extraño" de Martín Lienhard (1992) plantea que la escritura epistolar se inscribe en códigos radicalmente distintos a los del lenguaje indígena, en la medida en que los rasgos esenciales de su comunicación eran el carácter interno y oral, contrario a la exigencia que imponían los contextos insurreccionales y la correspondiente diplomacia entre "colonizado" y "colonizador". 
En el ejército había muchos españoles que sabían la lengua de los indios por ser naturales del Paraguay y de las Corrientes, donde, aún entre el vulgo español es vulgar esta lengua; pero la hablaban muy mal, haciendo un desconcertado mixto de guaraní y castellano, de suerte que ni los indios los entienden bien, ni ellos a los indios, y a veces, siendo intérpretes, dicen sí por no, y no por sí, como sucedió muchas veces en el progreso de las funciones del ejército.

En estos mismos términos expresará Bernardo Nusdorffer, jesuita de las Misiones, que, si bien tiene el mérito de haber rescatado las notas de Crisanto Nerenda -indígena que dejó un diario escrito en guaraní acerca de un enfrentamiento contra los portugueses en 1754-, define a los intérpretes de cartas como mentirosos:

Como este pueblo del Yapeyú ${ }^{14}$ es el que siempre tiene mucha comunicación con las ciudades cercanas de los Españoles por tierra y por agua, ay entre los Indios muchos que saben algo de lengua española. Estos en esta ocasión han sido los que mas daño han hecho, porque estos fueron los interpretes de las cartas, como después lo veremos y hallaban en ellas lo que ellas no decían y metían à la gente cien mil mentiras en la cabeza (Nusdorffer 252, citado por Wilde 2009 416).

Entre estos muros lingüísticos, desde la firma del Tratado y la comunicación de la ordenanza de abandono de las reducciones hasta el enfrentamiento entre la resistencia guaraní y la artillería luso-hispánica, se desliza un proceso que parte como batalla diplomática y claudica en la aplicación del exterminio como medida contra la desobediencia indígena. Esta "batalla diplomática" - término que tomamos de Melià - se compone por decenas de cartas dirigidas a la gobernación de Buenos Aires (aún no se formaba el Virreinato del Río de la Plata) o a la administración colonial portuguesa por parte de caciques y curas jesuitas que no lograron surtir efecto alguno. Es así como para 1754 el aspecto diplomático se encontraba agotado, dando paso a enfrentamientos que tendieron a confundir aún más la situación. No obstante, los líderes de cada bando estaban claramente definidos: entre los Siete Pueblos figuraron como capitanes Nicolás Ñeenguirú (natural de

\footnotetext{
${ }_{14}$ Yapeyú era la reducción más importante de los Treinta Pueblos de Misiones.
} 
Concepción) y Sepé Tiarajú (natural de San Luis), mientras que entre las fuerzas coloniales fue el militar y administrador colonial Antonio Gomes Freire de Andrade el encargado de la campaña portuguesa, y el gobernador platense José de Andonaegui de la hispánica. Por el lado de las autoridades civiles, Ricardo Wall tomó el cargo de ministro de Estado y Guerra del gobierno español; en el caso de los lusitanos, la presencia en la Corte de José de Carvalho e Mello (o Marqués de Pombal, primer ministro de Portugal en aquel entonces) incentivó las tendencias antijesuitas, agudizadas entre acusaciones y sospechas asociadas a las posibles riquezas que los ignacianos tenían en potestad de la Compañía (Amantino \& Pinheiro de Carvalho).

Los primeros enfrentamientos de 1754, considerados como la primera campaña de ocupación territorial por parte de lusitanos y españoles, acontecieron entre Río Pardo, Río Daymán y el asentamiento portugués en Yacuy. Los responsables de esta expedición, y por ende de las represalias contra la resistencia indígena, fue la gobernación de Buenos Aires, quienes hicieron llegar a Gomes Freire la orden de retroceder para articular una nueva campaña. Sin embargo, reticente a abandonar el espacio ganado, los portugueses firman un tratado bilingüe con los caciques y capitanes guaraníes que sirvió como tregua al fijar el paso de Yacuy como el nuevo límite, sellando el pacto con una misa, música y cantos ceremoniales el 18 de noviembre de 1754 (Quarleri 2009 265).

Una falsa sensación de resolución primó durante los siguientes meses, hasta que llegó a las reducciones la noticia de los movimientos militares que estaban preparando los ejércitos luso-hispánicos, esta vez aliados en la expedición y con equipamientos más contundentes y numerosos. En diciembre de 1755, José de Andonaegui dirige las tropas a Montevideo, donde se une al gobernador José Joaquín de Viana, formando entre ambos un ejército de 1.670 hombres que, luego, en Santa Tecla, ad portas de la Estancia de San Miguel, se fusiona con las milicias portuguesas dirigidas por Gomes Freire, sumando un total de 2.770 soldados. Ante semejante escenario, las alianzas indígenas se expanden más allá del espacio misionero, estableciendo lazos con los "infieles", categoría en la que entraban minuanes, charrúas y guenoas.

Los eventos de los meses siguientes quedarán registrados en distintos medios, siendo los principales las cartas y los diarios de guerra, 
documentos en los que es posible apreciar tanto los límites discursivos como el planteamiento de lógicas ligadas a la sumisión, en el caso monárquico, o a la autonomía, en el caso indígena. Francisco Mateos, estudioso jesuita, recupera desde el Archivo de Indias, en su investigación sobre la historia del Paraguay jesuítico, una serie de textos en los que figura el diario de Andonaegui durante la expedición, narrando episodios que dejan entrever la relación de las autoridades con el mundo guaraní, al que ubicaban en la subalternidad. Así, a propósito de un momento de acampada, un 3 de febrero de 1756, el gobernador y sus tropas se encuentran con un grupo de indios:

Seguí la marcha y estando acampado me trajeron tres indios, que a todos acaricié e hice dieran de comer y a cada uno una camisa y un par de calzones, con lo que los despaché advertidos de decir a Zepe y caciques viniesen a rendirme la obediencia como a su Gobernador y Capitán General por el Rey, que si lo hacían los trataría con amor, que de lo contrario les haría experimentar todas las calamidades que trae consigo la guerra (Mateos 254).

Esta serie amor/sumisión/castigo es, efectivamente, un lugar común en la relación monárquica con lo indígena, articulada de tal modo que los crímenes fueran amparados en un margen de tolerancia que, al analizar los hechos, se vislumbra ilusorio y falso. De hecho, un enfrentamiento aislado ocurrido tres días después acabó con la vida de Sepé Tiarayú, el insigne guía y capitán, a quien no solamente logran batir con una lanza, sino también torturar y quemar cuando se encontraba en el lecho de su muerte, para luego decapitarlo y enterrar separadamente su cuerpo cercenado. Como se puede imaginar, la ausencia de un dirigente como Sepé se hizo notar, quedando el corregidor Nicolás Ñeenguirú como principal orientador del combate. Sin embargo, las fuerzas bélicas de las Coronas se abalanzaron contra la resistencia indígena un 10 de febrero, en lo que será recordado como la "Batalla de Caybaté". Desde la perspectiva de Andonaegui -quien por cierto celebra este movimiento militar como un hito en la historia americana, por sus virtudes estratégicas y magnitud de desplazamiento-, la avanzada de las tropas concretó su ataque tras advertir sucesivas veces a los indígenas que se fortificaban en el monte, pues contaban con escaso armamento respecto a la tecnología de los monárquicos. 
(...) viendo que continuaban los trabajos de su fortificación, mandé les disparasen un cañotazo con bala; aguantaron y tiróseles otros; mantuviéronse firmes; los portugueses dispararon cuatro y los míos uno más; huyeron los indios, a quienes se les siguió la caballería de las dos naciones a toda rienda y una y otra a buen paso la infantería de entrambas llegaron a su campo, que estaba atrincherado de cuarteles; pasó adelante, encontró una zanja en que se habían refugiado muchos indios, la que atacaron los españoles, y otra los portugueses; en las dos mataron muchos (Id. 256).

La cifra de indígenas muertos fue de 1.311, en los cálculos presentados por Andonaegui ${ }^{15}$. Entre los españoles, tres muertos y diez heridos; entre los portugueses, cinco soldados muertos y un coronel. Este trágico encuentro sepultó la resistencia e impulsó la ocupación de los territorios. Pero, así como figuraron documentos de índole militar, también es posible ubicar y consultar los pronunciamientos indígenas que pulularon en torno a esta serie de eventos. En su compilación, Mateos titula un documento del siguiente modo: “Traducción de un papel de origen indígena relativo a la oposición que hacían los Guaraníes de los siete pueblos de Misiones, oponiéndose a que fuesen entregados a los portugueses". Cada documento, originalmente escrito en guaraní, era traducido adjuntando una nota que certificaba la verosimilitud de la versión castellana, "acorde al sentido del escrito". En el caso del escrito citado, se puede apreciar el uso de un razonamiento teológico que contrapone la doctrina cristiana con los mandatos del Rey:

Este mandato no es de Dios, sino del demonio: nuestro Rey anda por el camino de Dios y no del demonio, esto es lo que siempre oímos: nuestro Rey, aunque miserables y desdichados vasallos suyos, siempre nos ha tenido amor como a tales; nunca nuestro buen Rey mande que unos infelices sean perjudicados en sus haciendas y desterrados sin haber más motivo que servirle siempre que se ha ofrecido, y así no le creeremos jamás cuando diga: Vosotros, indios, dad vuestras tierras y cuanto tenéis a los portugueses. No lo creere-

15 Esta cifra oscila entre 600 y 1.500 según otras fuentes. El historiador Carlos Teschauer (citado en Wilde 2015 415) en sus estudios sobre Rio Grande do Sul, señala que la cifra podría haber ascendido a 1.700 . 
mos nunca: no ha de ser: si acaso la quieren comprar con su sangre, nosotros todos los indios las hemos de comprar (Id. 258).

En similar sentido, dos días antes de la batalla, Valentín Ibaringua, mayordomo de la estancia de San Miguel, escribe una carta a Sepé Tiarayú informándole sobre el escaso conocimiento que tenían sobre el avance de las tropas monárquicas. Escribe en guaraní, luego traducido por los padres jesuitas:

Por amor de Dios, os pido, no os dejes engañar de esa gente que os aborrece, si por ventura les escribieses alguna carta, manifiéstales el grande sentimiento que de su vida tienes y hazle conocer el poco miedo que os causan y la muchedumbre que somos, y que cuando esta multitud nuestra no fuera tanta, no los temeríamos por tener en nuestra compañía a la Santísima Virgen y a todos los Santos. Si cogieres alguno, preguntadle todo lo que hace al caso. El que me hiciste pedir por artillero, ahora llegar del pueblo, y prontamente te lo despachare, ahora te envío una bandera con el retrato de Nuestra Santísima. De nuestro pueblo, no hay novedad alguna que participarte. Tened gran confianza en las oraciones de todos los del pueblo, en especial de las criaturas inocentes, pues todos se emplean en encomendaros a Dios (citado en Quarleri 2009 302).

Dispersados los indígenas de las misiones, mientras los muertos en el campo de batalla quedan sepultados en el mismo sitio donde se les dio muerte, comienza la ocupación durante los meses siguientes. En la reducción de San Miguel, un 12 de febrero del mismo año, Primo Ibarenda escribió al gobernador Andonaegui para interpelarlo sobre las razones que impulsaron los mandatos de desplazamiento por parte del Rey:

(...) el buen deseo de nuestro Rey se ve bien que hará enviando allá nuestros papeles y sabiendo nuestro buen modo; vos también habéis visto nuestros papeles y te decimos la suma verdad: aquí no habéis de hallar tierras para todos nosotros, cuanto más para nuestros animales; no somos nosotros solos los de los 7 pueblos, sino 12 más están echados a perder, cuando nos queráis quitar nuestras tierras. Señor Gobernador, si no quisiereis oír estas nuestras razones todos nosotros ponemos en manos de Dios, porque es quien 
hace todas las cosas, él si es el que sabe nuestro yerro; a nuestro Rey no le hemos faltado en nada, por eso tenemos en él confianza (Mateos 246).

Sin embargo, dada la imagen que del indígena se habían formado las autoridades, la reacción hacia estos alegatos era nula. En cambio, hacia el 8 de marzo, es posible leer una carta de José de Andonaegui a los "Reverendos Padres Curas de los siete pueblos rebeldes":

(...) ruego a V. V. R. R. atiendan con todo esfuerzo, y charidad, a evitar tantos daños, y escándalos, pues aunque tuvieran presente la multitud de viudas, niños y huérdanos, que con la muerte de 1500 indios de esos pueblos, se originan de esta rebelión, me pareze debieran V. V. R. R. por sus altos exercicios de charidad, evittarlo por todos los medios posibles, como creo que el saserdosio es para mitigar los pecados entre Dios, y el hombre (Id.250).

Y agrega más adelante:

(...) si prosiguen en tales temeridades marcharé luego, luego con mi tropa y la de Portugal para que sufran el castigo justo que merecen. Todavía, R. R. P. P., la clemente de R. está dispuesta a admitir en su gracia y generosidad la summición debida a su soberanía; y prosiguiendo con la temeridad bárvara presente, esperen el justo castigo tan meresido que amenaza a toda esta Provinzia y a V. V. R. R. (Id. 250).

Como se puede apreciar, no basta con que una lengua sea "elevada" al rango letrado si quienes la enuncian son sujetos carentes de derecho. De ahí que una de las claves para adentrarse en eventos de esta índole sea una de las preguntas fundamentales del ámbito de lo político, a saber, la capacidad autonómica de las sociedades. No obstante, esto no puede ser analizado sin antes comprender las texturas que adquiere la guerra en contextos de autonomía, respecto de situaciones en las que el ejercicio de la dominación y la aplicación de la sumisión son principales ejes de movilización. En esto radica nuestra duda sobre "los belicosos pueblos" narrados en las historias civiles, en cuanto no es posible imaginar sus condiciones bélicas sin caer en las mismas lógicas del aparato estatal-colonial, novedoso enemigo que, desde la Conquista hasta nuestros días, ha ejercido el etnocidio de distintas formas. Lo mismo ocurre con las reductivas categorías como "indio", 
"salvaje", "infantil", por nombrar algunas, características dentro de la narrativa tanto científica ilustrada como epistolar ${ }^{16}$.

\section{A modo de cierre: guerra y alianza}

Entre otros aspectos de igual relevancia, es interesante reflexionar sobre las formas de alianza que adquirió cada bando: mientras los jesuitas lidiaban contra la antipropaganda divulgada en círculos europeos y se exculpaban de responsabilidad durante el levantamiento, las monarquías generaban un pacto que terminó por enfocarse contra el enemigo "interno", aunque fronterizo. En cambio, las alianzas indígenas, solapadas por la historiografía, demostraron que la construcción de solidaridades, con base en intereses políticos o relaciones de parentesco, eran los modos constituyentes e internos de los pueblos de las Misiones. Contrario al relato que otorga protagonismo a los jesuitas, tanto en la construcción y gestión del espacio misional como en la sublevación contra el Tratado de Madrid ${ }^{17}$, las articulaciones desplegadas por guaraníes fieles e infieles se presentan unidas por una memoria que transita acorde con un relato en el que se distingue un enemigo común - la infamia de los portugueses-, coordinando alianzas que, sin remitirse a un ethos guerrero específico (Wilde 2009 165), conforma un cuerpo de resistencia distinto a la táctica militar luso-hispánica, aun-

16 Por ejemplo, el padre Luis Escandón, contemporáneo a los sucesos esbozados anteriormente e integrante de las misiones, plantea respecto al pueblo guaraní: "es verdad, y no exagerada, que generalmente ninguna de esta gente tiene más capacidad, inteligencia y juicio, que entre nosotros, en Europa, los niños" (citado en Furlong 74). A esta "cortedad de entendimiento" se agrega la cualidad bárbara o salvaje, entrevista en José Cardiel en su defensa jesuita, pero que también tuvo resonancia en la historia natural y civil del docto padre Pedro Lozano: "Hablando de todas estas naciones en general, en cuanto vivían en su gentilidad, eran fieras salvajes é inhumanas; ni aun á lo natural se puede decir que vivían, porque algunos eran caribes, especialmente los guaraníes, de quienes sus descendientes, los chiriguanos heredaron la costumbre de comer carne humana (...)" (Lozano 382). Pedro Lozano, cabe señalar, llegó aproximadamente en 1717 al Río de la Plata, dedicándose a detallar los sucesos históricos hasta 1745, periodo durante el cual recorrió las misiones y dictó cátedras de filosofía y teología en la Universidad de Córdoba, entre otras actividades que elevaron su reconocimiento como intelectual letrado.

17 Efectivamente, en el relato general sobre las Misiones, el indígena es un sujeto pasivo y sumiso (Wilde 2011), motivo que permitió afirmar que el rol de los jesuitas durante la rebelión fue protagónico. Sin embargo, esta cinematográfica afirmación forma parte de las invenciones que circularon en Europa, comparables quizás con el mito de "Nicolás I", rey del Paraguay, ilusión inspirada en Nicolás Neengirú, supuesto primer rey indígena en América. 
que con rasgos comunes, considerando que, durante el siglo y medio de las misiones, allí se formaron cuadros militares de guaraníes que en diversas ocasiones expulsaron a invasores, sobre todo portugueses, quienes ya en 1680 habían fundado Colonia de Sacramento en un estratégico punto del Río de la Plata.

Pese a las diferencias de época y contexto, los ecos que rastreamos en 1756 entre las bifurcaciones del etnocidio y la ilustración vuelven a retratar los escenarios donde la obediencia es el bastión que impone los circuitos de relación social. ¿Cómo pensar, entonces, con Voltaire y Rousseau, sobre la base del silogismo leibniziano de "todo está bien"? Si Dios existe, es perfecto. Permanecer en esta afirmación implica estar en el lado de la razón, decidir según ideales de perfección, representada política y militarmente con base en estructuras de reducción, sumisión y disciplina. Tanto la etnografía estatal como la reducción de lenguas nativas a gramáticas y diccionarios figuran como modos de representación en los que la identidad se define de acuerdo con una determinada razón universal acoplada a la construcción de naciones ${ }^{18}$. Captar la amplitud de las textualidades del siglo XVIII —que llegó a abrir surcos ilustrados más allá de los colonos y sus descendencias, entre imprentas itinerantes y epístolas diplomáticas redactadas por indígenas-, implica torcer narrativas forjadas en los nudos de la clasificación y ampliar la comprensión de lo político en las fronteras coloniales, comprendiendo que se trató de espacios permeados por fuerzas plurales, cuyo registro escasamente se vislumbra en los escritos de la época, ausentándose del relato patriótico enarbolado por los próceres emancipadores que protagonizaron el siglo XIX americano.

A este periodo le sigue la firma de un nuevo tratado, el Tratado de San Ildefonso (1777), que devuelve dichos territorios a la administración española, aunque tras las batallas de 1753-1756 y la expulsión de la orden jesuita las reducciones comenzaron un proceso de desintegración:

18 En el caso del método ilustrado desenvuelto por los funcionarios de la Compañía de Jesús, resulta fundamental mencionar la influencia perspectivista de Gottfried Leibniz, perspectivismo del "detalle", como observa Foucault, y que es "la minucia de los reglamentos, la mirada puntillosa de las inspecciones, el poner bajo control las menores partículas de la vida y del cuerpo" y que "darán pronto, dentro del marco de la escuela, del cuartel, del hospital o del taller un contenido laicizado, una racionalidad económica o técnica a este cálculo místico de lo ínfimo y del infinito" (Foucault 162). 
de los 30.000 desplazados, retorna menos de la mitad (Wilde 2009 415). Las causas, como es evidente, remiten al éxodo hacia montes o poblados mestizos o criollos, donde existía un mercado libre del trabajo. Este paisaje respondía a una nueva etapa de modernización, que imponía la liberalización del mercado y la superación del sistema económico cerrado de la comunidad, propio de la Colonia. Nuevas leyes se promulgan respecto a la condición indígena, tanto en el lado español como en el portugués, distinguiendo esta coyuntura como la "posibilidad de ir y venir de un lado para otro, pudiendo, en muchos casos, pasar sin mayores problemas de vasallos del rey español al monarca portugués y viceversa" (Frühauf). Hacia 1767, se concreta la expulsión de los jesuitas. Las reducciones cambian de administración y ordenan su estructura orgánica bajo otros principios. Algunas quedan en ruinas, otras se convierten en el cimiento de futuras ciudades (Alden).

No obstante, en Europa el saber ilustrado progresa. La expulsión de eruditos jesuitas (clasificados como científicos) generará en las siguientes décadas contraposiciones entre las narrativas criollas y las fabulaciones que estudiosos europeos venían desarrollando a partir de las informaciones provenientes de las exóticas tierras del Nuevo Mundo. De un modo u otro, surgirán otras formas de reducción, siendo la del "ciudadano" la categoría que por antonomasia comenzará a dar sentido al Estado moderno emancipado, vinculando a los individuos y familias con un supra aparato encargado del orden y la estabilidad social. Este vínculo jerárquico, que permanece pese a las reformas económicas y jurídicas, es la huella común entre la Colonia y su subsecuente paso a la colonialidad, considerando al mismo tiempo el desarrollo continuo del militarismo y de las instalaciones de ejes de explotación económica que hoy en día pueden señalarse con claridad.

\section{Bibliografía}

Aínsa, Fernando. «La utopía americana del cristianismo social (15131577)». América Latina: Palavra, Literatura e Cultura. Ana Pizarro (ed.). São Paulo: UNICAMP, 1993. 85-109.

Alden, Dauril. The Making of an Enterprise: The Society of Jesus in Portugal, Its Empire, and Beyond, 1540-1750. Stanford: Stanford University Press, 1996. 
Amantino, M. y Pinheiro de Carvalho, M. «La famosa riqueza de los jesuitas y la expulsión. Algunos aspectos». IHS. Antiguos jesuitas en Iberoamérica 4.1 (2016): 5-30.

Arinos de Melo Franco, Afonso. O índio brasileiro e a Revoluçao Francesa. As origens brasileiras da teoria da bondade natural. 1937. Rio de Janeiro: Topbooks, 2000.

Armani, Alberto. Ciudad de Dios y Ciudad del sol. El "Estado" jesuita de los guaraníes (1609-1768). 1977. México, D.F.: FCE, 1996.

Astrain, Antonio. Jesuitas, guaraníes y encomenderos: historia de la compañía de Jesús en el Paraguay. Asunción: Centro de Estudios Paraguayos Antonio Guasch, 1996.

Cardiel, José. Declaración de la verdad contra un libelo infamatorio impreso en portugués contra los PP. jesuitas misioneros del $\mathrm{Pa}$ raguay y Marañon. 1758. Buenos Aires: Imprenta de J. Alsina, 1900.

Clastres, Pierre. La sociedad contra el Estado. Barcelona: Monte Ávila, 1978.

Clavigero, Francisco Javier. Historia antigua de México. México: Porrúa, 1974.

Cordeiro Ferreira, Andrey. Tutela e resistência indigena: etnografia e história das relaçoes de poder entre los Terena y el Estado Brasilero. São Paulo: Editora da Universidade de São Paulo, 2013.

Deleuze, Gilles. Curso sobre Rousseau. La moral sensitiva o el materialismo del sabio. Buenos Aires: Cactus, 2016.

Foucault, Michel. Vigilar y castigar: el nacimiento de la prisión. Buenos Aires: Siglo XXI Editores, 1978.

Frühauf, Elisa. "Ser índio" na fronteira: limites e possibilidades. Rio da Prata, c. 1750-1800». Nuevo Mundo Mundos Nuevos (2011): 1-13.

Furlong, Guillermo. Misiones y sus pueblos de guaranies. Buenos Aires: Lumicop y Cía., 1962.

Gil, F. M. «De la diferencia entre lo temporal y eterno. Crisol de desengaños con la memoria de la eternidad, postrimerías humanas y principales misterios divinos, de Juan Eusebio Nieremberg S. J. Introducción». Nieremberg, J. E. De la diferencia entre lo temporal y eterno. Primera edición facsimilar en conmemoración al Bicentenario de la Revolución de Mayo. Buenos Aires: 
Instituto Bonaerense de Numismática y Antigüedades, Bolsa de Comercio de Buenos Aires, Bolsa de Comercio de Rosario, 2010. XXV-LXX.

Golin, Tau. A Guerra Guaranítica. Como os exércitos de Portugal e Espanha destruíram os Sete Povos dos jesuitas e indios guaranis no Rio Grande do Sul (1750-1761). Porto Alegre: Editora da Universidade, 1999.

Góngora, Mario. Estudios sobre la historia colonial de Hispanoamérica. Santiago de Chile: Editorial Universitaria, 1998.

Gumilla, José S.J. El Orinoco Ilustrado y defendido. Caracas: Fuentes para la historia Colonial de Venezuela, 1963.

Hachim, L. y Hurtado, P. «El discurso factual y ficcional en la narrativa colonial hispanoamericana: Naufragios [1542] de Alvar Núñez Cabeza de Vaca e Infortunios de Alonso Ramírez [1690] de Carlos de Sigüenza y Góngora». Catedral Tomada 6.10 (2018): 172-188.

Hemming, John. «Los indios y la frontera en el Brasil colonial.» Leslie Bethel. Historia de América Latina. Barcelona: Crítica, 1990. 189-228.

Hemming, John. Red Gold. The conquest of the brazilian indians. Cambrige: Harvard University Press, 1978.

Henis, Tadeo. Efemérides de la Guerra de los Guaraníes desde el año de 1754, ó Diario de la Guerra del Paraguay. Escrito por el Padre Tadéo Henis, Regular de la Compañía, y Cura del Pueblo de San Estanislao. Madrid: Imprenta Real de la Gaceta, 1770.

Hernández Sánchez-Barba, M. Historia de América. América europea II. Madrid: Alhambra, 1986.

Hernández, Pablo. Organización social de las doctrinas guaranies de la Compañía de Jesús. Vol. Libro segundo. Barcelona: Gustavo Gili, 1913. 2 vols.

Huffine, K. «Raising Paraguay from decline: memory, ethnography, and natural history in the eighteenth-century accounts of the Jesuit Fathers». Luis Millones Figueroa y Domingo Ledezma (eds.). El saber de los jesuitas, historias naturales y el Nuevo Mundo. Madrid: Iberoamericana, 2005. 279-302.

Klaiber, J. «Misiones exitosas y menos exitosas: los jesuitas en Mainas, Nueva España y Paraguay». M. Marzal y L. Bacigalupo. Los jesuitas y la modernidad en Iberoamérica. Lima: Fondo Edi- 
torial de la Pontificia Universidad Católica del Perú; Universidad del Pacífico; Instituto Francés de Estudios Andinos, 2007. 323-334.

Kratz, Guillermo. El tratado hispano-portugués de límites de 1750 y sus consecuencias. Estudio sobre la abolición de la Compañía de Jesús. Vol. IV. Roma: Instituti Historici Societatis Iesu, 1954.

Lienhard, Martín, ed. Testimonios, cartas y manifiestos indígenas. Caracas: Ayacucho, 1992.

Lozano, Pedro. Historia de la conquista del Paraguay, Río de la Plata y Tucumán. Tomo primero. Buenos Aires: Casa Editora "Imprenta Popular", 1873.

Lynch, John. América Latina entre colonia y nación. Barcelona: Grijalbo, 2001.

Mateos, Francisco. Historia de la Compañía de Jesús en la Provincia del Paraguay (Argentina, Paraguay, Uruguay, Perú, Bolivia y Brasil) según los documentos originales del Archivo General de Indias (1751-1760). Vol. VIII. Consejo Superior de Investigaciones Científicas, Instituto Santo Toribio de Mogrevejo, 1949.

Martínez Solares, José Manuel. Los efectos en España del terremoto de Lisboa (1 de noviembre de 1755). Madrid: Dirección General del Instituto Geográfico Nacional, 2001.

Melià, Bartomeu. La lengua Guaraní del Paraguay. Madrid: MAPFRE, 1992.

Molina, Juan Ignacio. Compendio de la historia geográfica, natural y civil del Reyno de Chile. Santiago de Chile: Biblioteca Bicentenario, 2010.

Muratori, L. A. El cristianismo feliz en las misiones de la Compañía de Jesús en Paraguay. Santiago de Chile: DIBAM, 1997.

Neumann, Eduardo. "A escrita dos guaranis nas reduções: usos e funções das formas textuais indígenas - século XVIII». Topoi (2007): 49-79.

Nusdorffer, Bernardo. «Relación de todo lo sucedido en estas Doctrinas en orden a las mudanzas de los 7 Pueblos del Uruguai desde S. Borja hasta S. Miguel inclusive, que por el tratado Real, y línea divisoria de los limites entre las dos Coronas» Jaime Cortesão. Do Tratado de Madri à conquista dos Sete Povos (1750-1802). Rio de Janeiro: Biblioteca Nacional, 1969. 252. 
Quarleri, Lia. «Crónicas de un conflicto: encrucijadas metodológicas a partir del estudio de la "guerra guaranítica"». Bernardino Colvero, Ronaldo y Rodrigo F. Maurer. Missões em Mosaico. Da interpretação à prática: um conjunto de experiências. Porto Alegre: Faith, 2011. 123-137.

Quarleri, Lia. Rebelión y Guerra en las fronteras del Plata. Guaranies, Jesuitas e Imperios coloniales. Buenos Aires: FCE, 2009.

Quijano, Aníbal. «Colonialidad del poder, cultura y conocimiento en América Latina». Dispositio 24.51 (1999): 137-148.

Rousseau, J.-J. Escritos polémicos. Madrid: Tecnos, 1994 [1756].

Velasco, Juan de. Historia del Reino de Quito. Caracas. Biblioteca Ayacucho, 1981.

Voltaire y J.-J. Rousseau. En torno al mal y la desdicha; Voltaire-Rousseau. Ed. Alicia Villar. Madrid: Alianza Editorial, 1995.

Wilde, Guillermo. «De las crónicas jesuíticas a las "etnografías estatales": realidades y ficciones del orden misional en las fronteras ibéricas». Nuevo Mundo Mundos Nuevos (2011).

Wilde, Guillermo. «Orden y ambigüedad en la formación territorial del Río de la Plata a fines del siglo XVIII». Horizontes Antropológicos 19 (2003): 105-135.

Wilde, Guillermo. Religión y poder en las misiones de guaranies. Buenos Aires: SB, 2009. 